\title{
Extensão Universitária e Desenvolvimento Local Sustentável: Uma revisão da
}

\section{literatura}

\author{
University Outreach and Local Sustainable Development: A literature review \\ Extensión Universitaria y Desarrollo Local Sostenible: Una revisión de la literatura
}

Recebido: 20/04/2021 | Revisado: 28/04/2021 | Aceito: 11/05/2021 | Publicado: 28/05/2021

\author{
Marcelo Wanderley Dantas \\ ORCID: https://orcid.org/0000-0003-0133-2878 \\ Universidade de Pernambuco, Brasil \\ E-mail: marcelo.wanderley@upe.br \\ Mariana Guenther \\ ORCID: https://orcid.org/0000-0002-3104-3105 \\ Universidade de Pernambuco, Brasil \\ E-mail: mariana.guenther@upe.br
}

\begin{abstract}
Resumo
As Instituições de Ensino Superior (IES) são a base da construção dos conhecimentos científicos e tecnológicos que, em última análise, irão impulsionar o desenvolvimento local. Neste contexto, a Extensão Universitária atua como uma ponte, conectando os resultados das pesquisas produzidas dentro das IES às demandas da sociedade, além de atuar como uma poderosa ferramenta de ensino prático, fundamental para a formação dos estudantes. O objetivo deste estudo foi realizar uma revisão da literatura sobre o panorama histórico da Extensão Universitária, tanto no cenário nacional quanto mundial, bem como sobre a evolução dos conceitos de desenvolvimento econômico, sustentável e local, a fim de compreender o potencial da Extensão Universitária como promotora do Desenvolvimento Local Sustentável. Para tanto foi realizada pesquisa bibliográfica e documental. A partir desta pesquisa, concluímos que ao atuar diretamente em questões educacionais, econômicas, sociais, ambientais e culturais das localidades e regiões onde as Instituições de Ensino Superior encontram-se inseridas, a Extensão Universitária se revela como um importante instrumento propulsor do desenvolvimento local, construindo, em parceria com as comunidades beneficiadas, soluções inovadoras e capazes de resolver ou atenuar os problemas que as afligem.
\end{abstract}

Palavras-chave: Extensão universitária; Desenvolvimento local sustentável; Instituições de ensino superior.

\begin{abstract}
Higher Education Institutions (HEIs) are the basis for building scientific and technological knowledge that will ultimately drive local development. In this context, the University Extension acts as a bridge, connecting the results of research produced within the HEIs to society demands, as well as acting as a powerful practical teaching tool, crucial for student training. The objective of this study was to carry out a literature review on the historical panorama of University Extension, both nationally and worldwide, as well as on the evolution of the concepts of economic, sustainable and local development, to understand the potential of University Extension as promoter of Sustainable Local Development. For this purpose, bibliographic and documentary research was carried out. From this research, we conclude that through direct action on educational, economic, social, environmental and cultural issues in the localities and regions where Higher Education Institutions are located, the University Extension represents an important driving force for local development, building, in partnership with the benefited communities, innovative solutions capable of solving or mitigating the problems afflicting them.
\end{abstract}

Keywords: University outreach; Sustainable local development; Higher education institutions.

\section{Resumen}

Las Instituciones de Educación Superior (IES) son la base para la construcción de conocimientos científicos y tecnológicos que, en última instancia, impulsarán el desarrollo local. En este contexto, la Extensión Universitaria actúa como puente, conectando los resultados de la investigación producida dentro de las IES con las demandas de la sociedad, además de actuar como una poderosa herramienta práctica docente, imprescindible para la formación de los estudiantes. El objetivo de este estudio fue realizar una revisión de la literatura sobre el panorama histórico de la Extensión Universitaria, tanto a nivel nacional como mundial, y sobre la evolución de los conceptos de desarrollo económico, sostenible y local, para comprender el potencial de la Extensión Universitaria. como promotor del Desarrollo Local Sostenible. Para ello se realizó una investigación bibliográfica y documental. De esta investigación se concluye que al actuar directamente sobre temas educativos, económicos, sociales, ambientales y culturales en las localidades y regiones donde se ubican las Instituciones de Educación Superior, la Extensión Universitaria se revela como un importante motor impulsor del desarrollo local, construyendo, en alianza con las comunidades beneficiadas, soluciones innovadoras capaces de resolver o mitigar sus os problemas.

Palabras clave: Extensión universitária; Desarrollo local sostenible; Instituciones de educación superior. 


\section{Introdução}

Ao longo de sua concepção histórica, a Extensão Universitária passou por diversos momentos que vão do assistencialismo religioso à interação dialógica (Oliveira \& Goulart, 2015). Atualmente, a Extensão Universitária é compreendida como o "braço" institucional que, articulado ao ensino e à pesquisa, busca inter-relacionar as Instituições de Ensino Superior (IES) com as comunidades circunvizinhas e os contextos socioeconômicos locais onde as mesmas encontramse inseridas. Ao assumir um papel de destaque no contexto universitário, por meio do compartilhamento dos resultados das pesquisas produzidas, a Extensão Universitária busca atender às demandas sociais existentes, de modo a possibilitar a emancipação dos indivíduos e a promoção do desenvolvimento das localidades (Paula, 2013).

Nessa perspectiva, as IES são, em sua maioria, responsáveis pela atração de investimentos, pela construção de conhecimentos científicos e tecnológicos e pela indução do desenvolvimento das localidades onde estão inseridas (Freire \& Holanda, 2019). Outrossim, ao possibilitar aos estudantes a vivência de experiências significativas que promove reflexões da atualidade com base nas experiências e conhecimentos produzidos e acumulados, a Extensão Universitária procura associar o desenvolvimento de uma formação acadêmica comprometida com as necessidades nacionais, regionais e locais (Fernandes et al., 2012). Como os saberes estão relacionados à instrumentalização da missão institucional e ao impacto social decorrente da indissociabilidade do ensino, da pesquisa e da extensão no processo educativo, ressalta-se que, à medida que se busca aprofundar e aprimorar os conhecimentos e saberes e associá-los à sua prática, maiores são as chances e possibilidades de se possuir habilidades e desenvolver competências diferenciadas (Silva, Siqueira \& Barros, 2019).

Associado à realidade da práxis educativa e de seus respectivos impactos, o desenvolvimento local surge como um processo de transformação que envolve o ser humano como principal beneficiário da mudança, o qual está relacionado com a melhoria da qualidade de vida da coletividade ou de um determinado grupo de pessoas (comunidade), levando em consideração a transformação social, cultural, econômica e política de uma localidade (Castilho et al., 2009; Serpa et al., 2021). Nesse sentido, como boa parte dos estudos sobre a Extensão Universitária concentra seus esforços para a construção de sua historicidade e para a sua contextualização nas IES, incipientes, ainda, são os estudos dedicados a investigar e analisar os desdobramentos das ações extensionistas desenvolvidas pelas IES para a promoção do desenvolvimento local das comunidades circunvizinhas às instituições.

Diante desse contexto, o presente estudo tem como reflexão a seguinte indagação: como a Extensão Universitária se relaciona com a promoção do Desenvolvimento Local Sustentável?

Face ao exposto, nesse estudo, buscou-se analisar, a partir de uma construção teórica, a relação entre a Extensão Universitária como promotora do Desenvolvimento Local Sustentável, através de uma abordagem metodológica de caráter descritivo e indutivo, onde foi possível, por meio da pesquisa bibliográfica e documental, realizar inferências e induções para conclusões acerca da relação entre as dimensões temáticas contidas na pesquisa. Sendo assim, ao longo deste trabalho, apresenta-se, como discussão, a historicidade da Extensão Universitária em âmbito nacional e mundial, a evolução dos conceitos de desenvolvimento e a relação entre a Extensão Universitária como promotora do Desenvolvimento Local Sustentável. Por fim, traz-se à tona as considerações finais a que se chegou a partir desta pesquisa.

\section{Metodologia}

O presente estudo foi delineado a partir do desenvolvimento de uma pesquisa pautada na construção teórica relacionada às dimensões sustentabilidade, desenvolvimento local, extensão e o arcabouço legal que norteia a Extensão Universitária. Assim, esta pesquisa tem caráter descritivo, tendo em vista que possui objetivos bem definidos e foi conduzido para a descrição e análise dos dados captados (Ana \& Lemos, 2018). 
No que concerne às técnicas utilizadas, este estudo se baseou na documentação indireta, cujos dados coletados são coletados por terceiros e se tornaram fontes para a pesquisa em epígrafe. Foram contemplados, nesta pesquisa, a pesquisa bibliográfica e documental, sendo a pesquisa bibliográfica realizada por meio de artigos científicos, originários de sites acadêmicos como o Google Acadêmico e o Scielo, e a pesquisa documental por meio de documentos oficiais e norteadores da extensão no âmbito nacional e local.

A pesquisa bibliográfica teve como objetivo relacionar as dimensões abordadas na presente pesquisa, de modo a compreender, de forma mais aprofundada, os saberes em obras que tratam do mesmo tema ou de temas próximos ao da pesquisa (Tonozi-Reis, 2009). A análise documental buscou selecionar, categorizar, classificar e tratar os dados correlacionando-os pelas semelhanças. Essa análise se dá de modo que o conteúdo será apresentado de uma forma diferente da original, ou seja, diferente dos dados brutos (Marconi \& Lakatos, 2017).

O método de abordagem adotado foi o método indutivo, ou seja, considerando que foram extraídos elementos informativos dos documentos originais que possuíssem relação com extensão e desenvolvimento local e, a partir de dados particulares de cada documento selecionado, realizou-se inferências e induções para conclusões, de modo geral, acerca da relação integradora que possuem as dimensões da pesquisa. Segundo as bases lógicas da investigação, a escolha de um estudo indutivo ocorre quando o estudo é conduzido apenas a conclusões prováveis, cujo objetivo dos argumentos é levar a conclusões do qual o conteúdo é mais amplo do que o das premissas nas quais se basearam (Marconi \& Lakatos, 2017).

\section{Referencial Teórico}

Nesta seção são apresentadas e discutidas as bases e os pressupostos teóricos acerca do tema em questão, razão pela qual este tópico encontra-se dividido em três etapas: a primeira discorre sobre o panorama histórico da Extensão Universitária, no Brasil e no mundo; a segunda apresenta a evolução dos conceitos de desenvolvimento: econômico, sustentável e local; e, por fim, representando a abordagem central deste trabalho, a terceira etapa procura compreender a promoção do Desenvolvimento Local Sustentável por meio da Extensão Universitária.

\subsection{A Extensão Universitária no Brasil e no mundo: uma perspectiva histórica}

Antes mesmo da existência do conceito de Extensão Universitária, práticas relacionadas à extensão remontam às primeiras escolas gregas, que ofertavam suas aulas abertas ao público, e às universidades europeias medievais, que levavam seus conhecimentos às classes mais pobres, com ações de caráter religioso e filantrópico, de cunho assistencialista. (Serrano, 2012, p. 83; Oliveira \& Goulart, 2015).

Com registros que datam da segunda metade do século XIX, as primeiras concepções da Extensão Universitária demonstram características peculiares de duas vertentes: uma de origem europeia e outra de origem americana. Originárias da Inglaterra, as primeiras manifestações da Extensão Universitária ocorreram a partir de iniciativas das Universidades de Cambridge, em 1871, e de Oxford, no mesmo período, por meio da oferta de cursos de extensão voltados às classes sociais menos favorecidas (Paula, 2013).

A necessidade de contribuição e compartilhamento dos conhecimentos produzidos pelas universidades com os setores sociais populares impulsionou a vertente europeia da Extensão Universitária, associando-a ao surgimento das universidades populares europeias, na perspectiva de que o alcance social, por parte das universidades, só seria possível por intermédio de sua extensão (Abad, 2015).

Com a disseminação da prática por todo o continente europeu, a Extensão Universitária chegou aos Estados Unidos, de forma pioneira, em 1892, na Universidade de Chicago, impulsionada pela criação da American Society for Extension of University Teaching. Em 1903, a prática americana foi caracterizada como uma experiência bem-sucedida, desenvolvida pela 
Universidade de Wisconsin, ao colocar seus professores como técnicos especialistas do governo do estado, o que lhe conferiu prestígio e visibilidade nacional, sendo chamada de "Wisconsin Idea" (Paula, 2013).

Ao assumir o constructo baseado em duas vertentes, uma de origem inglesa e outra de origem norte-americana, a Extensão Universitária, no primeiro momento, estabeleceu o engajamento da universidade junto aos segmentos sociais, como o estado e a igreja, com vistas a oferecer contrapontos às consequências negativas decorrentes do capitalismo na era da revolução industrial. No segundo momento, a Extensão Universitária buscou mobilizar a universidade para as questões socioeconômicas, no sentido da transferência de tecnologia e da aproximação da universidade com o setor empresarial, demonstrando uma vocação rigorosamente liberal desse modelo (Paula, 2013).

Na América Latina, a Extensão Universitária ganhou destaque na Argentina, em 1918, por meio do Manifesto de Córdoba. Concebido por estudantes universitários argentinos, o Manifesto de Córdoba, precursor da reforma universitária, enfatizava a necessidade de relação entre universidade e movimentos sociais. Entendia-se que a materialização dessa relação universidade-sociedade se daria através da Extensão Universitária, com vistas ao fortalecimento da universidade, a partir da projeção da cultura universitária junto às classes populares (Melo Neto, 2002; Melo, 2010).

Segundo Oliveira e Goulart (2015), as fases e faces da concepção da Extensão Universitária podem ser sintetizadas em cinco períodos, um pré-extensionista, caracterizado pelo assistencialismo religioso das Universidades Medievais, e quatro períodos extensionistas, que vão desde o surgimento da Extensão Universitária, na Inglaterra, até a sua chegada na América Latina, conforme pode ser visualizado na Figura 1.

Figura 1: Contexto mundial da Extensão Universitária.

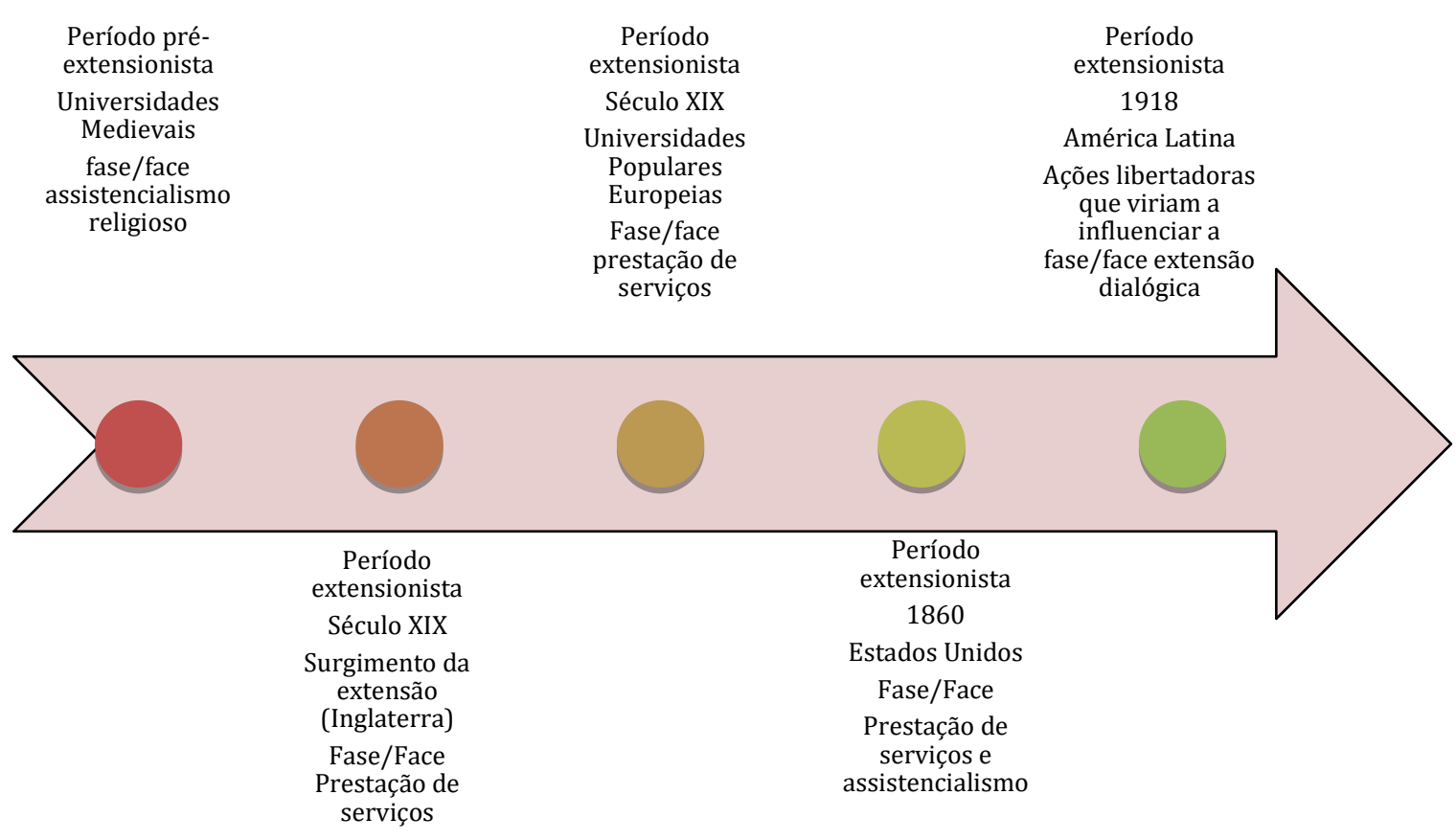

Fonte: Adaptado de Oliveira e Goulart (2015).

No Brasil, as primeiras manifestações da Extensão Universitária datam do início do século XX e demonstram, ao longo de sua trajetória, fortes características e influências das vertentes extensionistas europeia, americana e argentina (Frizzo, Marin \& Schellin, 2016). 
As primeiras práticas brasileiras, no âmbito da extensão, ocorreram, no ano de 1911, inicialmente, em São Paulo, com a criação da Universidade Livre de São Paulo, e, posteriormente, no Rio de Janeiro, e em Minas Gerais, nas cidades de Viçosa e Lavras. Nesse período, a Extensão Universitária demonstrava conotação típica da Extensão Universitária europeia, voltada à educação continuada e à educação das classes populares, assim como da Extensão Universitária americana, voltada à prestação de serviços na área rural (Paula, 2013).

Legalmente, a introdução da Extensão Universitária, na legislação educacional brasileira, só ocorreu no ano de 1931, a partir da publicação do Decreto-lei $\mathrm{n}^{\circ}$ 19.851, de 11 de abril de 1931, que dispôs sobre o Estatuto das Universidades Brasileiras (Brasil, 1931). Nesse mesmo período, influenciados pelos pressupostos do Manifesto de Córdoba, proveniente da luta de estudantes universitários argentinos em favor de uma maior relação entre as universidades e os movimentos sociais, estudantes brasileiros se organizaram e criaram a União Nacional dos Estudantes (UNE), favoráveis a uma universidade que se mostrasse a serviço do povo brasileiro (Kochhann, 2017). Esse movimento foi muito importante para o desenrolar da Extensão Universitária brasileira, pois, em 1938, no segundo Congresso Nacional dos Estudantes, foi aprovado o plano de sugestões para uma Reforma Educacional Brasileira (Barbosa, 2012).

Com a promulgação da Lei $\mathrm{n}^{\circ} 5.540 / 68$, responsável pela Reforma Universitária, foram fixadas normas de organização e funcionamento do ensino superior brasileiro e se estabeleceu a obrigatoriedade da extensão em todas as IES, estendendo as suas atividades de ensino e pesquisa à comunidade por meio de cursos e serviços especiais (Brasil, 1968).

Durante o período da ditadura militar, após o golpe de 1964, evidenciaram-se importantes experiências extensionistas, de forma individualizada, realizadas por IES, cujo destaque se deu por suas influências marcantes no cenário nacional. Como exemplo, pode-se destacar o Centro Rural Universitário Federal do Rio Grande do Norte (CRUTAC-RN), o Campus Avançado e o Projeto Rondon (Melo Neto, 2002; Melo, 2010).

Em 1970, dado o crescimento das atividades extensionistas, fomentado e consolidado com a participação do Governo Federal, em comum acordo com o Ministério da Educação (MEC), criou-se a Coordenação de Atividades de Extensão (CODAE), com o objetivo de organizar e institucionalizar os mecanismos de operacionalização da extensão, dando origem ao Plano de Trabalho de Extensão Universitária (Kochhann, 2017).

No ano de 1987, a partir da organização de um conselho, impulsionados pelos movimentos de institucionalização e operacionalização da Extensão Universitária, os Pró-Reitores das Universidades públicas criaram o Fórum Nacional de PróReitores de Extensão das Universidades Públicas Brasileiras (FORPROEX), hoje chamado de Fórum de Pró-Reitores de Extensão das Instituições Públicas de Educação Superior Brasileiras. Foi no primeiro Encontro de Pró-Reitores de Extensão das Universidades Públicas Brasileiras, realizado em 1987, que se definiu o conceito de Extensão Universitária e que se apresentou a busca pela associação entre a teoria e a prática educativa, destacando-se a importância da indissociabilidade entre o ensino, a pesquisa e a extensão, comprometida com um processo educativo, cultural e científico, que busque viabilizar a relação transformadora entre universidade e sociedade, com ênfase na interação dialógica entre o conhecimento acadêmico e o popular prático (FORPROEX, 1987).

Nesse sentido, a Extensão Universitária passou a ser estabelecida como uma via de mão-dupla entre a comunidade acadêmica e a sociedade, por meio de um processo interdisciplinar, que favorece a visão integrada do social, de modo a possibilitar a construção de um aprendizado teórico-prático, que estabeleça a troca de saberes sistematizados/acadêmicos e popular, resultante do confronto com a realidade brasileira e regional (FORPROEX, 1987).

Em conformidade com os conceitos pactuados pelo FORPROEX, ratificando o que já vinha sendo preconizado pelas normas anteriores, em 1988, a Constituição da República Federativa do Brasil (Brasil, 1988) definiu o gozo da autonomia didático-científica, administrativa e de gestão financeira e patrimonial das universidades, estabelecendo que as mesmas deveriam obedecer ao princípio da indissociabilidade entre ensino, pesquisa e extensão, e, ainda, estabeleceu a possibilidade de 
recebimento de apoio financeiro do poder público para as atividades universitárias de pesquisa e extensão, como atestam os artigos 207 e 213 , 2 :

Art. 207 As universidades gozam de autonomia didático-científica, administrativa e de gestão financeira e patrimonial, e obedecerão ao princípio de indissociabilidade entre ensino, pesquisa e extensão.

Art. 213 Os recursos públicos serão destinados às escolas públicas, podendo ser dirigidos a escolas comunitárias, confessionais ou filantrópicas, definidas em lei que: [...]

[...] $\S 2^{\circ}$ As atividades de pesquisa e extensão e de estímulo e fomento à inovação realizadas por universidades e/ou por instituições de educação profissional e tecnológica poderão receber apoio financeiro do poder público.

O seu reconhecimento constitucional e os progressos advindos do papel do Ministério da Educação e do FORPROEX contribuíram para o avanço da Extensão Universitária no Brasil e para a criação do Programa de Fomento à Extensão Universitária (PROEXTE), no ano de 1993. As contribuições do programa de fomento estão associadas à "elaboração técnicoconceitual, especificamente, a definição das diretrizes e objetivos da Extensão Universitária, dos tipos de ações a serem desenvolvidas e da metodologia a ser adotada em sua implantação" (FORPROEX, 2012, p.15).

Alguns anos depois, já em 1996, com a promulgação da Lei de Diretrizes e Bases da Educação Nacional, Lei no 9.394/96, a Extensão Universitária foi estabelecida como uma das finalidades da universidade, sendo instituída a possibilidade de apoio financeiro do poder público, inclusive, mediante bolsas de estudo (Brasil, 1996).

Outro passo significativo para a institucionalização da Extensão Universitária foi dado, no ano 1998, com a elaboração e aprovação, por parte do FORPROEX, do Plano Nacional de Extensão. Foi através desse plano que se deram a possibilidade de unicidade nacional dos programas temáticos, a garantia de recursos financeiros destinados à execução de políticas públicas correlatas, o reconhecimento da Extensão Universitária não só como atividade acadêmica, mas também como prática de uma Universidade cidadã, e a viabilização de interferência na solução dos problemas sociais do país (FORPROEX, 2001).

Nesta mesma perspectiva, corroborando o fortalecimento e desenvolvimento da Extensão Universitária Brasileira, no ano de 2001, foi aprovada a Lei $n^{\circ}$ 10.172/01 - Plano Nacional de Educação (Brasil, 2001), para o decênio 2001-2010, onde ficou estabelecido que, do total dos créditos exigidos para a graduação no ensino superior do país, no mínimo, $10 \%$ teria que ser reservado para a atuação dos estudantes em ações extensionistas, como atesta a Meta 23:

23. Implantar o Programa de Desenvolvimento da Extensão Universitária em todas as Instituições Federais de Ensino Superior no quadriênio 2001-2004 e assegurar que, no mínimo, 10\% do total de créditos exigidos para a graduação no ensino superior no país será reservado para a atuação dos alunos em ações extensionistas.

Assim, no começo do século XXI, a Extensão Universitária já demonstrava forte densidade institucional, devido aos atos normativos legais e suas regulamentações, demonstrando forte superação de que a sua concepção não estaria apenas relacionada à disseminação do conhecimento acadêmico, por meio de cursos, conferências ou seminários, à prestação de serviços, por meio de assistências, assessorias e consultorias, e à difusão de conhecimento e cultura, por meio de eventos diversos e divulgação de produções artísticas (FORPROEX, 2012).

Como é destacado na Política Nacional de Extensão Universitária (2012):

A Extensão Universitária tornou-se o instrumento por excelência de inter-relação da Universidade com a sociedade, de oxigenação da própria Universidade, de democratização do conhecimento acadêmico, assim como de (re)produção desse conhecimento por meio da troca de saberes com as comunidades. Uma via de mão dupla ou, como se definiu nos anos seguintes, uma forma de interação dialógica que traz múltiplas possibilidades de transformação da sociedade e da própria Universidade Pública (FORPROEX, 2012). 
Cada vez mais essa concepção tem sido fortalecida, visto que, recentemente, com a publicação da Resolução $\mathrm{n}^{\circ}$ 7, de 18 de dezembro de 2018, da Câmara de Educação Superior do Conselho Nacional de Educação, foram estabelecidas as diretrizes para a extensão na educação superior brasileira, a partir da regulamentação da Meta 12.7 da Lei no 13.005/2014, ficando definidos os princípios, os fundamentos e os procedimentos que devem ser observados no planejamento, nas políticas, na gestão e na avaliação das instituições de educação superior de todos os sistemas de ensino do país.

\subsection{As faces do desenvolvimento}

Historicamente, a evolução do conceito de desenvolvimento se deu com a Revolução Industrial, entre os séculos XVIII e XIX, responsável pela substituição de um processo produtivo, até então, artesanal, familiar e de subsistência, por um processo produtivo fabril e capitalista. Voltado para o trabalho assalariado e com uso de máquinas, esse período, intitulado de industrial, ficou caracterizado como marco histórico global no processo de desenvolvimento devido às novas estruturas e formas de organização do trabalho e às grandes mudanças tecnológicas e econômicas (Motta \& Vasconcellos, 2006).

Compreendido como um processo social global, pautado em concepções ou ideais coletivamente partilhados durante a construção do processo histórico-social, o conceito de desenvolvimento está intrinsecamente relacionado ao aspecto macrossocial. A ideia central do conceito de desenvolvimento não está apenas associada à quantidade e à qualidade da produção de bens e serviços, mas à sua contribuição para o bem-estar da coletividade, bem como de sua distribuição entre os grupos de pessoas (Vieira \& Santos, 2012).

A concepção histórica do conceito de desenvolvimento relaciona-se com os aspectos históricos vivenciados e estes podem estar relacionados às problematizações inerentes às fases da conceituação, que perpassam por questões econômicas, ambientais e locais.

\subsubsection{Desenvolvimento econômico}

Os primórdios do desenvolvimento econômico estão associados à formação dos estados nacionais europeus que possibilitaram a criação de mercados seguros, fruto de uma organização política e econômica decorrente da associação aristocrática e burguesa, que culminou numa Revolução Capitalista denominada Revolução Industrial. Destaca-se que a industrialização foi viabilizada a partir do momento em que as nações se dotaram de estados e formaram estados-nação (Bresser-Pereira, 2006).

Oriundo de um processo histórico capitalista, pautado nas mudanças decorrentes da industrialização e da reestruturação do trabalho, o conceito de desenvolvimento não é consenso entre os estudiosos do capitalismo contemporâneo (Silva, Oliveira \& Araújo, 2012). Existe uma grande confusão em relação ao uso dos conceitos de desenvolvimento econômico e crescimento econômico. O conceito de desenvolvimento econômico está associado à ideia do crescimento econômico acompanhado de melhoria significativa no padrão de vida da população e por alterações na estrutura econômica e social, a partir de uma distribuição mais equitativa das riquezas produzidas. Já o conceito de crescimento econômico está relacionado ao aumento da capacidade produtiva da economia, ou seja, da capacidade de produção de bens e serviços de uma nação ou área econômica. Esse crescimento pode ser calculado com base na evolução anual do Produto Nacional Bruto - PNB ou pelo Produto Interno Bruto - PIB (Vieira \& Santos, 2012).

Pode-se inferir que a definição de crescimento econômico se traduz em mais do mesmo, enquanto a definição de desenvolvimento econômico se relaciona com transformações estruturais voltadas ao coletivo, tendo por base conhecimentos que permitam hierarquizar problemas e soluções de modo a facilitar a coordenação entre os atores sociais (Erber, 2011). O trabalho produtivo, com aumento dos investimentos em capitais produtivos, a especialização da mão-de-obra e a divisão do trabalho constituem a riqueza de uma nação (Silva, Oliveira \& Araújo, 2012). 
Para os economistas clássicos, o desenvolvimento econômico é fruto do resultado da organização produtiva, com ênfase na produção, estando ligado diretamente ao processo de crescimento (Vieira \& Santos, 2012). Seguindo a linha de raciocínio da visão global de desenvolvimento, o desenvolvimento econômico pode ser definido como um processo de mudança social decorrente da introdução de inovações tecnológicas no sistema produtivo, onde um número crescente de necessidades humanas, preexistentes ou criadas, são satisfeitas (Barbosa, 2009).

Contrárias às ideias clássicas do conceito de desenvolvimento econômico, que, até então, preconizavam a ótica capitalista da maximização do lucro, foram constituídas críticas à lógica capitalista decorrente do crescimento da produção, sem que ocorresse a extensão dos ganhos pertinentes à ampliação da produção para o conjunto da sociedade (Vieira \& Santos, 2012). Nessa perspectiva, o capitalismo decorrente da Revolução Industrial foi responsável pelo crescimento da produção e, por consequência, da forte concentração funcional da renda, não contribuindo para a melhoria da qualidade de vida da maior parte das pessoas, os trabalhadores, quando o critério é a quantidade de riqueza produzida no estágio de produção econômica capitalista (Silva, Oliveira \& Araújo, 2012).

Ao longo da história, durante muitos anos, agentes econômicos, empresas, estados e indivíduos pautaram as suas decisões econômicas com base apenas nos benefícios materiais, sem se preocupar com as demais questões relacionadas ao desenvolvimento. É com base no senso de coletividade contido no conceito de desenvolvimento e nas lacunas sociais e ambientais provenientes da concepção do desenvolvimento econômico, decorrente do processo de industrialização, que surgiram representações e movimentos favoráveis a novas concepções de desenvolvimento.

\subsubsection{Desenvolvimento sustentável}

As primeiras discussões sobre as questões ambientais surgiram, no ano de 1960, decorrentes da degradação ambiental, proveniente do desenfreado processo de industrialização e desenvolvimento econômico, com o propósito de alertar a humanidade sobre o seu comprometimento futuro devido à utilização irracional dos recursos naturais disponíveis (Kovalski, 2016).

Em 1972, durante a primeira Conferência das Nações Unidas sobre o Meio Ambiente Humano (CNUMA), como reflexo das discussões do Clube de Roma, em 1968, destacou-se a existência de alarmantes problemas de ordem social, econômica e ambiental, que viriam comprometer as gerações futuras, caso fossem mantidos os padrões de desenvolvimento vigentes, trazendo à tona reflexões sobre a questão dos limites de crescimento (Krüger, 2001). O modelo desenvolvimentista vigente à época apontava para a insustentabilidade, visto que o seu desenvolvimento era direcionado para a necessidade de uma expansão infinita, frente a um mundo finito (Kovalski, 2016).

Em virtude da consolidação do relatório da ONU, referente à $1{ }^{\text {a }} \mathrm{CNUMA}$, princípios associados aos direitos humanos, gestão dos recursos naturais, redução da poluição e relação entre ambiente e desenvolvimento foram estabelecidos junto às questões ambientais internacionais, desencadeando debates relacionados aos custos socioambientais e à conscientização das limitações ecológicas ao crescimento (Organização Das Nações Unidas [ONU], 1972; Van Bellen \& Petrassi, 2016). A questão apresentada não implicava em um crescimento nulo, mas em um crescimento que levasse em consideração a necessidade de prudência em relação à utilização dos recursos naturais, à promoção de uma maior equidade social e à gestão de políticas descentralizadas e economicamente solidárias (Vieira, 2009).

No ano de 1973, a partir da introdução do conceito de ecodesenvolvimento, ocorreram mudanças na orientação do debate sobre desenvolvimento e meio ambiente, voltadas para uma nova concepção de desenvolvimento (Lima, 2006). Em um sentido mais amplo, esse conceito inclui a relação de reciprocidade entre a sociedade e o meio ambiente, ao estabelecer uma conexão entre os problemas que afetam o meio ambiente, tratados pela ecologia, mas que também afetam o homem (Van Bellen \& Petrassi, 2016). 
Destarte, os novos caminhos para o desenvolvimento apontavam para questões relativas à satisfação das necessidades básicas, à solidariedade com as gerações futuras, à participação da população envolvida, à preservação dos recursos naturais e do meio ambiente, à elaboração de um sistema social, que garanta emprego, segurança social e respeito a outras culturas e a programas de educação (Silva, 2013). Assim, à discussão inicial de escassez de recursos naturais foram introduzidas as dimensões social e econômica à questão ambiental (Sachs, 2015).

Anos depois, com a publicação da declaração de Cocoyoc, em 1974, elaborada na Conferência das Nações Unidas sobre o Comércio e Desenvolvimento, em Cocoyoc, no México, e do relatório Dag-Hammarskjöld, em 1975, reforçaram-se as concepções preconizadas pelo ecodesenvolvimento, com base na necessidade de redefinição do modelo de desenvolvimento, com vistas a um desenvolvimento que concebesse alternativas ecologicamente prudentes, equitativas socialmente, politicamente descentralizadas e economicamente solidárias (Organização das Nações Unidas [ONU], 1974; 1975; Van Bellen \& Petrassi, 2016).

Diante da necessidade de maior neutralidade entre discussões políticas e econômicas, voltadas à reorientação das políticas de desenvolvimento e sua relação direta com as questões ambientais, ocorreu, no ano de 1987, a substituição do termo ecodesenvolvimento por desenvolvimento sustentável.

No ano de 1987, ainda, a definição do conceito de desenvolvimento sustentável foi apresentada pela Comissão Mundial sobre o Meio Ambiente e Desenvolvimento (CMMAD), por meio do documento intitulado "Nosso Futuro Comum", também, conhecido como Relatório Brundtland. O desenvolvimento sustentável pode ser, portanto, entendido como "aquele que atende às necessidades do presente sem comprometer as possibilidades de as gerações futuras atenderem às suas necessidades" (Brundtland, 1987).

Além de conceituar o desenvolvimento sustentável, o Relatório Brundtland ampliou as discussões acerca da interrelação entre desenvolvimento e meio ambiente, a partir da adoção de uma visão mais global, que envolvia sustentabilidade, padrões de desenvolvimento, solidariedade e compromissos entre as nações desenvolvidas e subdesenvolvidas, atuais e futuras, de modo a serem tratadas questões como subdesenvolvimento, pobreza e degradação ambiental, dando uma nova visão à estratégia de desenvolvimento (Souza, 1994).

Outras importantes contribuições para o desenvolvimento sustentável foram apresentadas na $2^{\mathrm{a}}$ Conferência Mundial sobre Meio Ambiente e Desenvolvimento, mais conhecida como Eco-92 ou Rio-92, realizada em 1992, na Cúpula Mundial sobre o Desenvolvimento Sustentável (Rio+10), no ano de 2002, e na Conferência das Nações Unidas sobre o Desenvolvimento Sustentável, conhecida como Rio+20, realizada em 2012. Com a realização desses eventos, buscou-se promover a aceitação da ideia de desenvolvimento sustentável, reconhecer e compartilhar responsabilidades com o intuito de alterar as tendências dos impactos negativos sobre os recursos naturais, reforçar as discussões e compromissos assumidos frente à questão da sustentabilidade pelos setores privado e público e voltar o seu direcionamento à pobreza, à justiça social e ao crescimento e desenvolvimento econômico. (Feil \& Schreiber, 2017).

\subsubsection{Desenvolvimento local}

Por se tratar de um objeto de estudo relativamente recente, campo de análise, discussão e teorização, que não apresenta conceituação unânime entre os pesquisadores, o desenvolvimento local, para a maioria dos autores, é fruto da perspectiva da valorização humana como sujeito de seu próprio desenvolvimento (Castilho et al., 2009).

Os estudos sobre o desenvolvimento local apontam caminhos para as soluções inviáveis, ou sem o devido sucesso, decorrentes da busca pelo desenvolvimento por parte dos governos e empresas, sustentadas, na maioria das vezes, pelas preocupações convencionais de desenvolvimento econômico, que desconsideravam fatores defendidos pelos princípios da sustentabilidade (Dias, 2019). 
Nesse sentido, o desenvolvimento local pode ser compreendido como um processo de transformação voltado à melhoria de qualidade de vida de uma coletividade ou grupo de pessoas de uma determinada localidade, que envolve o ser humano como principal beneficiário da mudança. Por se tratar de um processo dinamizador da sociedade para a promoção de melhoria da qualidade de vida de uma comunidade, o desenvolvimento local é um processo de transformação social, cultural, econômico e político, cujos beneficiários são os indivíduos de uma sociedade (Castilho et al., 2009).

A ideia central do conceito de desenvolvimento local, como processo endógeno, está relacionada à diferenciação do que seria desenvolvimento local. Em outras palavras, o desenvolvimento local endógeno, de forma abrangente, diferencia-se entre o desenvolvimento no local e o desenvolvimento para o local (Ávila, 2005, 2012).

Nessa concepção, o desenvolvimento no local (DnL) consiste em:

um empreendimento ou iniciativa a que se atribui a qualificação "de desenvolvimento", por gerar emprego e expectativa de arrecadação de impostos e circulação de bens e dinheiro, mas que, em verdade, tem o local apenas como sede física. Só fica no local enquanto o lucro compensa. No momento em que a lucratividade baixa, ou quebra empresarialmente falando - ou vai embora, deixando à comunidade-localidade seus destroços-fantasmas, por vezes, muitos e graves problemas ambientais e, principalmente, enorme frustração na população. (Ávila, 2005, p. 70, 2012, p. 23-26).

Enquanto o desenvolvimento para o local (DpL) é definido pela seguinte ideia:

se refere à ideia de "desenvolvimento" que, além de se situar no local como sede física, gera atividades e efeitos benéficos às comunidades e aos ecossistemas locais, mas à maneira bumerangue: brota das instâncias promotoras, vai aos locais-comunidades, mas volta às instâncias promotoras em termos de consecução mais de suas próprias finalidades institucionais (as das instâncias promotoras, evidentemente) que do real, endógeno e permanente desenvolvimento das comunidades-localidades visadas (Ávila, 2005, p.73, 2012, p. 26-29).

Ambas as concepções são importantes para a criação das bases econômicas do desenvolvimento local endógeno, entretanto, o desenvolvimento no local e o desenvolvimento para o local buscam apenas situar a localidade (o local) onde ocorre o desenvolvimento e demonstrar as raízes históricas de caráter assistencialista e exploratória (Ávila, 2005, 2012). Fortalece-se essa visão ao afirmar que os desdobramentos do desenvolvimento local se deram a partir de duas frentes: uma de reprodução lógica capitalista em escala localizada (tradicional) e outra de tentativas contra hegemônicas (solidárias) (Martins, Vaz \& Caldas, 2010).

Analisadas as significações do desenvolvimento e do desenvolvimento local, pode-se inferir que o cerne do conceito de desenvolvimento local consiste no efetivo desabrochamento de uma comunidade específica, a partir da valorização das suas capacidades, competências e habilidades, capazes de contribuir para o rompimento de amarras, anteriormente, impostas pelo status quo de vida das pessoas (Ávila, 2005, 2012).

Com isso, tem-se a ativa colaboração dos agentes internos e externos, que possuem interesses comuns e se encontram situados em um espaço territorialmente delimitado, com identidade social e histórica, envolvidos no processo de desenvolvimento da localidade. Ao assumir essa configuração, o desenvolvimento local demonstra a capacidade de incrementar a cultura da solidariedade, de modo a promover o aproveitamento de potenciais próprios inerentes à localidade e de gerenciamento próprio de insumos e investimentos que dizem respeito à comunidade (Ávila, 2005, 2012).

Nesse sentido, a partir da identificação de que a concepção do conceito de desenvolvimento local está relacionada à integração dos diversos atores da sociedade e do envolvimento destes em relação ao conhecimento das demandas sociais locais, pode-se inferir que o desenvolvimento local pressupõe que os agentes da sociedade (governos, cidadãos, empresas e organizações da sociedade civil) de determinadas localidades devem estar integrados de modo a formarem um consenso sobre 
as características econômicas da região, bem como das oportunidades, para que as localidades se desenvolvam, segundo as suas peculiaridades (Han, 2009).

\subsection{A Extensão Universitária como promotora do Desenvolvimento Local Sustentável}

Compreendidas as bases históricas e conceituais sobre Extensão Universitária e Desenvolvimento Local, percebemos uma correlação clara e direta entre elas, uma vez que ambas mantêm seus esforços direcionados ao atendimento de demandas sociais decorrentes de um processo histórico de desigualdades proveniente do processo de desenvolvimento.

A educação é capaz de proporcionar a priorização pelo desenvolvimento local ou regional, por se configurar, na atualidade, como um dos instrumentos mais importantes para a promoção do desenvolvimento do país, por meio da valorização e empoderamento dos cidadãos, que permitem o fortalecimento e a eficácia das redes de capital social. Nessa perspectiva, com o acesso à educação, à ciência e à tecnologia, é possível, por parte do ser humano, a compreensão do mundo e o entendimento do seu papel nele (Sousa \& Freiesleben, 2018).

No Brasil, a promoção do desenvolvimento local e regional está, cada vez mais, relacionada com o papel das IES e, por consequência, das práticas extensionistas desenvolvidas por essas instituições, uma vez que, por meio da Extensão Universitária, as IES buscam estabelecer uma relação mais direta com a comunidade (Fernandes et al., 2012; Freire \& Holanda, 2019).

Estudos apontam que a chegada e a implantação de uma IES em uma determinada localidade representam um ganho significativo para o desenvolvimento local do entorno à unidade seja pela atração de investimentos e mão de obra qualificada, seja pela essência do trabalho desenvolvido pela instituição no âmbito do ensino, da pesquisa e da extensão e da promoção social (Goebel \& Miura, 2004; Hoff, Martin \& Sopenã, 2011; Silva, 2013; Oliveira Júnior, 2014; Sousa \& Freiesleben, 2018).

O conjunto das atividades desenvolvidas pelas IES assume uma importância estratégica relevante no processo de desenvolvimento, pois as atividades desenvolvidas pelas IES dão origem a uma força de atração de consumidores e empresas, contribuindo para o crescimento econômico-social local e regional (Oliveira Jr, 2014).

Nesse sentido, ressalta-se a importância do papel da pesquisa e da extensão nas IES para o estímulo ao desenvolvimento, a partir da busca por soluções técnicas e tecnológicas, que estendam os seus benefícios à comunidade. Dessa forma, as IES respondem, de forma ágil e eficaz, às demandas crescentes por recursos humanos, difundindo o conhecimento científico e proporcionando suporte aos arranjos produtivos locais (Sousa \& Freiesleben, 2018).

A Extensão Universitária possui, enquanto metas, o compromisso de dialogar com a sociedade, de responder às suas demandas e expectativas, além de reconhecer a sociedade em sua diversidade como sujeito de direitos e deveres e como portadores de valores e culturas legítimas. Possui, ainda, a meta de construir uma relação de compartilhamento entre os conhecimentos científicos e tecnológicos, produzidos nas IES, e os conhecimentos advindos das comunidades tradicionais, na perspectiva da promoção da interação dialógica em prol da liberdade e emancipação dos indivíduos (Paula, 2013). Todas essas metas se configuram como condições indispensáveis para o estímulo ao desenvolvimento local e para a melhoria da qualidade de vida das pessoas inseridas nas comunidades atendidas pelas IES.

As ações de extensão, de fato, incidem, de forma intervencionista, sobre questões atuais e fundamentais do nosso tempo, de modo a se refletir sobre o futuro das cidades, sobre o meio ambiente, o mundo do trabalho e a vida cultural (Paula, 2013) e, consequentemente, sobre o desenvolvimento das localidades. Dada a necessidade de rompimento de amarras e entraves, que dificultam a promoção do desenvolvimento e a valorização de um grupo em detrimento do individualismo, a Extensão Universitária se relaciona diretamente com o desenvolvimento local.

É através da Extensão Universitária que as IES buscam motivar e mobilizar os seus mais diversos atores para o enfrentamento de questões contemporâneas do ponto de vista da solidariedade e da sustentabilidade. É, ainda, por meio da 
Extensão Universitária que as IES buscam compartilhar, dialogar e interagir, tendo como referência os princípios que regem a Extensão Universitária brasileira: i) a indissociabilidade entre ensino, pesquisa e extensão; ii) a interação dialógica com a sociedade; iii) a inter e a transdisciplinaridade como princípios organizadores das ações de extensão; iv) a busca do maior impacto e da maior eficácia social das ações e v) a afirmação dos compromissos éticos e sociais da universidade (Paula, 2013).

Neste sentido, ao se relacionar com o desenvolvimento local, a Extensão Universitária assume um papel fundamental junto à sociedade, possibilitando a troca de saberes e experiências que têm por consequência a democratização do conhecimento comprometida com as necessidades nacionais, regionais e locais.

\section{Considerações Finais}

Dos seus primórdios aos dias atuais, a Extensão Universitária tem percorrido um longo e árduo caminho para ratificar a sua densidade institucional frente às dimensões acadêmicas do ensino e da pesquisa, e demonstrar a superação de que a sua concepção estaria associada, apenas, à disseminação do conhecimento acadêmico-científico, à prestação de serviços e à difusão da cultura. Muito além disso, a Extensão Universitária tem se apresentado como instrumento de interação dialógica entre as Instituições de Ensino Superior e a sociedade, a partir do estabelecimento de uma via de mão dupla, onde são asseguradas múltiplas possibilidades de transformação da sociedade e da própria universidade.

A partir da presente análise foi possível perceber que a Extensão Universitária e seus desdobramentos e impactos sociais revelam uma intervenção nas localidades em que as ações são direcionadas, de forma a construir soluções inovadoras e capazes de resolver ou atenuar problemas que afligem as comunidades beneficiadas por essas ações.

Com isso, as Instituições de Ensino Superior, por meio da Extensão Universitária, poderão ser propulsoras do Desenvolvimento Local Sustentável, a partir da parceria e envolvimento com as comunidades locais, promovendo espaços de interação, escuta e promoção de uma educação alimentada pelo saber que pode ser extraído e construído a partir daqueles que participam desse processo de desenvolvimento.

Diante da relevância do papel dos atores sociais na ampliação e participação de toda comunidade acadêmica na construção de uma extensão mais ativa e contextualizada, é necessário que as instituições incentivem e fomentem a inserção de estudantes, docentes, técnico-administrativo em projetos e atividades de extensão, contribuindo assim cada vez mais com o desenvolvimento local.

Este estudo exploratório servirá, portanto, de alicerce teórico para o desdobramento de pesquisas futuras que identifiquem de que forma as Instituições de Ensino Superior estão estimulando a participação de sua comunidade acadêmica em projetos, programas e atividades de extensão.

\section{Referências}

Abad, M. (2015). Extensão Universitária e sua Eficácia: estudo de caso do UnB Idiomas. (Dissertação de Mestrado, Faculdade de Economia, Administração e Contabilidade da Universidade de Brasília, Brasília, DF). https://repositorio.unb.br/bitstream/10482/21035/1/2015_MaristelaAbad.pdf

Ana, W. P. S., \& Lemos, G. C. (2018). Metodologia Científica: a pesquisa qualitativa nas visões de Lüdke e André. Revista Eletrônica Científica Ensino Interdisciplinar, 4(12), 531-541. https://doi.org/10.21920/recei72018412531541

Ávila, V. F. (2005). Cultura de subdesenvolvimento e desenvolvimento local. Edições UVA.

Ávila, V. F. (2012). Dupla relação entre educação e desenvolvimento local (endógeno-emancipatório). Paidéia, 9(12), 13-49.

Barbosa, D. P. (2009). Visões do desenvolvimento: as perspectivas de Celso Furtado e Douglass North sobre o desenvolvimento econômico. (Dissertação de Mestrado, Universidade Federal do Paraná, Curitiba, PR). https://acervodigital.ufpr.br/bitstream/handle/1884/24257/Disser tacao_DanielPBarbosa_Visoes\%20do\%20Desenvolvimento.pdf?sequence=1\&isAllowed=y

Barbosa, V. C. (2012). Extensão Universitária: proposição e validação de um instrumento de validação da percepção dos docentes. (Dissertação de Mestrado, Faculdade de Ciências Empresariais da Universidade FUMEC, Belo Horizonte, MG). https://repositorio.fumec.br/bitstream/handle/123456789/30 8/valeska_barbosa_mes_adm_2012.pdf?sequence=1\&isAllowed=y 
Bellen, H. M. Van; \& Petrassi, A. C. M. A. (2016). Dos limites do crescimento à gestão da sustentabilidade no processo de desenvolvimento. Revista NECAT, $5(10), 8-30$

Brasil. (1931). Governo Provisório da República dos Estados Unidos do Brasil. Decreto $n^{\circ} 19.851$, de 11 de abril de 1931. Dispõe que o ensino superior no Brasil obedecerá, de preferência, ao sistema universitário, podendo ainda ser ministrado em institutos isolados, e que a organização técnica e administrativa das universidades é instituída no presente Decreto, regendo-se os institutos isolados pelos respectivos regulamentos, observados os dispositivos do seguinte Estatuto das Universidades Brasileiras. https://www2.camara.leg.br/legin/fed/decret/1930-1939/decreto-19851-11-abril-1931-505837-publicacaooriginal-1pe.html

Brasil. (1968). Presidência da República. Lei $n^{\circ}$ 5.540, de 28 de novembro de 1968. Fixa normas de organização e funcionamento do ensino superior e sua articulação com a escola média, e dá outras providências. https://www2.camara.leg.br/legin/fed/lei/1960-1969/lei-5540-28-novembro-1968-359201publicacaooriginal-1-pl.html

Brasil. (1988). Presidência da República. Constituição da República Federativa do Brasil. https://www2.senado.leg.br/bdsf/bitstream/handle/id/518231/CF88_Livro_EC91_2016.pdf

Brasil. (1996). Presidência da República. Lei $n^{\circ}$ 9.394, de 20 de dezembro de 1996. Estabelece as diretrizes e bases da educação nacional. https://www2.camara.leg.br/legin/fed/lei/1996/lei-9394-20-dezembro-1996-362578-publicacaooriginal-1-pl.html

Brasil. (2001). Presidência da República. Lei $n^{\circ}$ 10.172, de 9 de janeiro de 2001. Aprova o Plano Nacional de Educação (PNE) e dá outras providências. https://www2.camara.leg.br/legin/fed/lei/2001/lei-10172-9-janeiro-2001-359024-publicacaooriginal-1-pl.html

Brasil. (2018). Câmara de Educação Superior do Conselho Nacional de Educação. Resolução $n^{\circ} 7$, de 18 de dezembro de 2018. Estabelece as diretrizes para a Extensão na Educação Superior Brasileira e regimenta o disposto na Meta 12.7 da Lei no 13.005/2014, que aprova o Plano Nacional de Educação - PNE 20142024 e dá outras providências. http://portal.mec.gov.br/index.php?option=com_docman\&view=download\&alias=104251-rces00718\&category_slug=dezembro-2018-pdf\&Itemid=30192

Bresser-Pereira, L.C. (2006). O conceito histórico de desenvolvimento econômico. FGV EESP - Textos para Discussão / Working Paper Series, 157, 1-24.

Brundtland, G. H. (1987). Our Common Future: Report of the World Commission on Environment and Development. Geneva, UN-Dokument A/42/427. http://www.un-documents.net/ocf-ov.htm

Castilho, M. A., Arenhardt, M. M., \& Le Bourlegat, C. A. (2009). Cultura e identidade: os desafios para o desenvolvimento local no assentamento Aroeira, Chapadão do Sul, MS. Interações (Campo Grande), 10(2), 159-169. https://doi.org/10.1590/S1518-70122009000200004

Dias, A. G. (2019). Desenvolvimento Local e Filosofia: convergências possíveis. (Dissertação de Mestrado, Universidade Católica Dom Bosco, Campo Grande, MS). https://site.ucdb.br//public/md-dissertacoes/1031305-dissertacao-antonio-garcia-dias.pdf

Erber, F. S. (2011). As convenções de desenvolvimento no governo Lula: um ensaio de economia política. Brazilian Journal of Political Economy, 31(1), 3155. https://doi.org/10.1590/S0101-31572011000100002

Feil, A. A., \& Schreiber, D. (2017). Sustentabilidade e desenvolvimento sustentável: desvendando as sobreposições e alcances de seus significados. Cadernos EBAPE.BR, 15(3), 667-681. https://doi.org/10.1590/1679-395157473

Fernandes, M. C., Silva, L. M. S., Machado, A. L. G., \& Moreira, T. M. M. (2012). Universidade e a extensão universitária: a visão dos moradores das comunidades circunvizinhas. Educação em Revista, 28(4), 169-194. https://doi.org/10.1590/S0102-46982012000400007

Fórum Nacional de Pró-Reitores de Extensão das Universidades Públicas Brasileiras. (1987). I Encontro de Pró-reitores de extensão das universidades públicas brasileiras. http://www.renex.org.br/documentos/Encontro-Nacional/1987-I-EncontroNacional-do-FORPROEX.pdf.

Fórum Nacional de Pró-Reitores de Extensão das Universidades Públicas Brasileiras. (2001). Plano Nacional de Extensão universitária: versão final. http://www.renex.org.br/documentos/Encontro-Nacional/1995-IX-Encontro-Nacional-do-FORPROEX.pdf.

Fórum Nacional de Pró-Reitores de Extensão das Universidades Públicas Brasileiras. (2012). Política Nacional de Extensão. http://www.renex.org.br/documentos/2012-07-13-Politica-Nacional-de-Extensao.pdf.

Freire, H. P., \& Holanda, V. C. C. (2019). Universidade pública e desenvolvimento local e regional: um estudo sobre a atuação da Universidade do Estado do Rio Grande do Norte - UERN. In Anais do XIII ENANPEGE da Associação Nacional de Pós-Graduação em Geografia. São Paulo, SP, Brasil.

Frizzo, G. F. E., Marin, E. C., \& Schellin, F. O. (2016). A extensão universitária como elementos estruturante da universidade pública no Brasil. Currículo sem Fronteiras, 16(3), 623-646.

Goebel, M. A., \& Miura, M. N. (2004). A universidade como fator de desenvolvimento: o caso do município de Toledo-PR. Expectativa, 3(3), 35-47. https://doi.org/10.48075/revex.v3i1.743

Han, G. W. S. (2009). Desenvolvimento local: os desafios frente à globalização hegemônica. Vitrine da Conjuntura, 2(2), 1-12.

Hoff, D. N., San Martin, A. S., \& Sopeña, M. B. (2011). Universidades e desenvolvimento regional: impactos quantitativos da Unipampa em Sant'Ana do Livramento. Redes, 16(3), 157-183. https://doi.org/10.17058/redes.v16i3.1699

Kochhann, A. (2017). A extensão universitária no Brasil: compreendendo sua historicidade. In Anais da VI Semana de Integração da Universidade Estadual de Goiás Câmpus Inhumas. (p. 546-557). Inhumas, GO, Brasil.

Kovalski, R. A. (2016). Desenvolvimento territorial sustentável: uma análise da evolução do pensamento humano em relação à consciência sobre o meio ambiente. Humanidades, 31(1), 101-120. https://doi.org/10.5020/23180714.2016.31.1.101-120 
Krüger, E. L. (2001). Uma abordagem sistêmica da atual crise ambiental. Desenvolvimento $e$ Meio Ambiente, (4), 37-43. https://doi.org/10.5380/dma.v4i0.3038

Lima, A. R. (2006). Desenvolvimento Local Integrado e Sustentável - DLIS: um olhar sob a perspectiva dos agentes implementadores. (Dissertação de Mestrado, Universidade Federal da Paraíba, João Pessoa, PB). https://repositorio.ufpb.br/jspui/bitstream/tede/7200/1/arquivototal.pdf

Macedo, R. C. (2015). Resenha: SACHS, Ignacy. Desenvolvimento: includente, sustentável, sustentado. Rio de Janeiro. Ed. Garamond. 151p. 2004. CampoTerritório: Revista De Geografia Agrária, 10(20). http://www.seer.ufu.br/index.php/campoterritorio/article/view/27656

Marconi, M. de A.; Lakatos, E. M. (2017). Fundamentos de metodologia científica. (8a ed.). São Paulo: Atlas.

Martins, R., Vaz, J., \& Caldas, E. (2010). A gestão do desenvolvimento local no Brasil: (des) articulação de atores, instrumentos e território. Revista de Administração Pública, 44(3), 559-590. https://doi.org/10.1590/S0034-76122010000300002

Melo Neto, J. F. (2002). Extensão Universitária: bases ontológicas. In J. F. Melo Neto (Org.), Extensão Universitária - diálogos populares (pp. 7-22). Editora Universitária da UFPB.

Melo, J. R. (2010). A extensão universitária na UFPE: uma análise sobre a produção extensionista na perspectiva docente 2004-2009. (Dissertação de Mestrado, Universidade Federal de Pernambuco, Recife, PE). https://repositorio.ufpe.br/bitstream/123456789/7153/1/arquivo349_1.pdf

Motta, F. C. P., \& Vasconcelos, I. F. G. (2006). Teoria geral da administração. (3a ed.). Pioneira.

Oliveira Jr, A. de. (2014). A universidade como polo de desenvolvimento local/regional. Caderno de Geografia, 24(1), 1-12. https://doi.org/10.5752/P.23182962.2014v24nespp1

Oliveira, F., \& Goulart, P. M. (2015). Fases e faces da extensão universitária: rotas e concepções. Revista Ciência em Extensão, 11(3), 8-27.

Organização das Nações Unidas. (1972). Report of the United Nations Conference on the Human Environment. Stockholm, A/CONF.48/14/Rev.1. https://undocs.org/en/A/CONF.48/14/Rev.1

Organização das Nações Unidas. (1974). United Nations Environment Programme: the Cocoyoc Declaration adopted by the participants in the UNEP/UNCTAD Symposium on "Patterns of Resource Use, Environment and Development Strategies" held at Cocoyoc, Mexico, from 8 to 12 October 1974. https://digitallibrary.un.org/record/838843

Organização das Nações Unidas. (1975). What Now - The 1975 Dag Hammarskjöld Report. http://www.daghammarskjold.se/wpcontent/uploads/2016/07/What-Now-1975.pdf

Paula, J. A. (2013). A extensão universitária: história, conceito e propostas. Interfaces, 1(1), 5-23.

Serpa, L. G., Machado, C. J. dos S., Nascimento, G. A. do, \& Almeida, A. R. de. (2021). Por uma educação a favor da práxis: ação, educação e cultura. Research, Society and Development, 10(1), e54210112104. https://doi.org/10.33448/rsd-v10i1.12104

Serrano, R. M. S. M. (2012). Avaliação Institucional da Extensão Universitária na UFPB: a regulação e a emancipação. (Tese de Doutorado, Universidade Federal da Paraíba, João Pessoa, PB). https://repositorio.ufpb.br/jspui/bitstream/tede/4689/1/Arquivototal.pdf

Silva, E. P. da, Oliveira, E. A. de A. Q., \& Araújo, E. A. S. de. (2012). O conceito de desenvolvimento econômico regional: uma revisão teórica. In The 4th International Congress on University Industry Cooperation. Taubaté, SP, Brasil.

Silva, W. F. (2013). A dodiscência na Educação Profissional e Tecnológica para o Desenvolvimento Local Sustentável no Instituto Federal de Educação, Ciência e Tecnologia de Pernambuco, Campus Ipojuca. (Dissertação de Mestrado, Universidade de Pernambuco, Recife, PE). https://w1files.solucaoatrio.net.br/atrio/upe-gdls_upl//THESIS/72/dissertaco_willyanne.pdf

Silva, W. F. da, Siqueira, N. C. de, \& Barros, W. B. de. (2019). A Indissociabilidade do Ensino, Pesquisa e Extensão na perspectiva de uma formação secretarial sustentável. Revista Expectativa, 18(2), 28-48. https://doi.org/10.48075/revex.v18i2.20357

Sousa, F. E., \& Freiesleben, M. (2018). A educação como fator de desenvolvimento regional. Revista da FAE, 21(2), 163-178.

Souza, A. L. L. (1994). Meio ambiente e desenvolvimento sustentável: uma reflexão crítica. SEBRAE.

Vieira, E., \& Santos, M. (2012). Desenvolvimento Econômico Regional - uma revisão histórica e teórica. Revista Brasileira de Gestão e Desenvolvimento Regional, 8(2), 344-369.

Vieira, P. F. (2009). Políticas ambientais no Brasil: do preservacionismo do desenvolvimento territorial sustentável. Política \& Sociedade, 8(14), 27-75. https://doi.org/10.5007/2175-7984.2009v8n14p27

Viero, T. V., \& Tauchen, G. (2012). Programa de Extensão Universitária: análise das concepções e perspectivas no âmbito da educação em ciências. In Anais do IX ANPED SUL - Seminário de Pesquisa em Educação da Região Sul. Caxias do Sul, RS, Brasil. 